\title{
$\mathrm{T}_{\mathrm{FH}}$ cells link gut microbiota and arthritis
}

The gut microbiota is known to be required for the development of autoimmune arthritis in the $\mathrm{K} / \mathrm{BxN}$ mouse model of rheumatoid arthritis, but the mechanisms underlying this link are not well understood. New research indicates that the gut microbiota regulates arthritis development via follicular $\mathrm{T}$ helper cells ( $\mathrm{T}_{\mathrm{FH}}$ cells), independently of type 17 helper $\mathrm{T}$ cells ( $\mathrm{T}_{\mathrm{H}} 17$ cells).

"The relationship of the gut microbiota and follicular T helper cells has not been well studied," explains Haochu Huang, corresponding author of the study published in The Journal of Immunology. To shed light on the matter, Huang and colleagues tested the requirement of $\mathrm{T}_{\mathrm{H}} 17$ and $\mathrm{T}_{\mathrm{FH}}$ cells for the development of arthritis in $\mathrm{K} / \mathrm{BxN}$ mice, and how the gut microbiota modulates the differentiation of these cells. "We took a genetic approach, using knockout mice to modulate the differentiation or effector function of certain $\mathrm{T}$ cell subsets," Huang recounts.

Using this approach, the researchers showed that IL-17-deficient K/BxN mice develop arthritis similarly to their IL-17-sufficient littermates. Moreover, treatment with antibiotics starting from birth (which effectively eliminated segmented filamentous bacteria from the gut) prevented the development of arthritis in both groups of mice, suggesting that the microbiota promotes arthritis development independently of IL-17.

Serum titres of autoantibodies against glucose-6-phosphate isomerase (GPI, the autoantigen of the $\mathrm{K} / \mathrm{BxN}$ model) were significantly lower in antibiotic-treated mice than in untreated mice. Treatment with antibiotics also reduced the

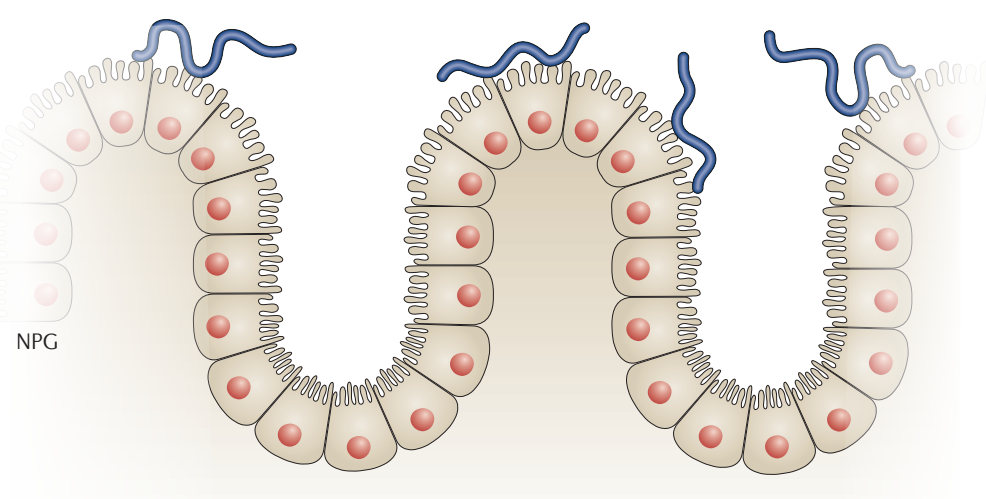

proportion and number of germinal centre $\mathrm{B}$ cells and $\mathrm{T}_{\mathrm{FH}}$ cells, whereas untreated $I l 17^{-/-}$mice had normal germinal centres and $\mathrm{T}_{\mathrm{FH}}$ cells in secondary lymphoid organs.

To formally determine whether $\mathrm{T}_{\mathrm{FH}}$ cells are required for arthritis, the researchers used T-cell-specific deletion of Bcl6, a transcription factor essential for the differentiation and function of $\mathrm{T}_{\mathrm{FH}}$ cells, in a T-celltransfer-induced arthritis model. Unlike control (Bcl6-sufficient) cells, Bcl6-deficient $\mathrm{T}$ cells did not induce arthritis in recipient mice. Serum titres of anti-GPI IgG were also significantly lower after transfer of Bcl6-deficient T-cells. Notably, T cells deficient for Bcl6 could differentiate into $\mathrm{T}_{\mathrm{H}} 17$ cells but not into $\mathrm{T}_{\mathrm{FH}}$ cells post-transfer.

Together, the results highlight the effects of the intestinal microbiota on the differentiation of T-cell subsets and arthritis development. "Gut microbiota regulates the differentiation of follicular helper T cells, a $\mathrm{T}$ cell subset that plays an important role in helping $\mathrm{B}$ cells in antibody responses," concludes Huang.

\section{Sarah Onuora}

ORIGINAL ARTICLE Block, K. E. et al. Gut microbiota regulates $\mathrm{K} / \mathrm{BxN}$ autoimmune arthritis through follicular helper T but not Th17 cells.

J. Immunol. http://dx.doi.org/10.4049/ jimmunol.1501904 (2016) 